\title{
Nicotine and Smoking Do Not Decrease Basal Gastric Mucosal Blood Flow in Anesthetized Rats
}

\author{
MARIE E. ROBERT, FELIX W. LEUNG, and PAUL H. GUTH
}

\begin{abstract}
The literature regarding the effect of nicotine and cigarette smoke on gastric blood flow is conflicting. The hydrogen gas clearance technique was used to measure the effects of nicotine and cigarette smoke on basal gastric mucosal blood flow in anesthetized rats. Blood flow was measured before, during, and after treatment with either intravenous nicotine ( 4 or $40 \mu \mathrm{g} / \mathrm{kg} / \mathrm{min}$ ) or inhaled cigarette smoke (nicotine or nicotine free). Neither intravenous nicotine nor cigarette smoke significantly altered gastric mucosal blood flow. On the other hand, hypotension produced by hemorrhage significantly decreased mucosal blood flow $(\mathrm{P}<0.05)$. Thus the technique used could detect a decrease in blood flow. These findings indicate that in the anesthetized rats, hypotension but not intravenous nicotine or cigarette smoke, in the doses given, reduce gastric mucosal blood flow.
\end{abstract}

The effect of nicotine and cigarette smoke on gastrointestinal physiology has been extensively studied. Smoking increases gastroduodenal reflux $(1,2)$. Variable effects on acid secretion have been reported (3-5). In addition, nicotine (6) and cigarette smoke (7) potentiate the formation of secretagogueinduced gastroduodenal lesions in experimental animals.

In recent years interest has focused on the effect of nicotine on gastric blood flow. Several investigators have examined this question with conflicting results. Jacobson and Pawlik (4) reported that in dogs nicotine increased total gastric blood flow as measured by an electromagnetic flow probe. On the

Manuscript received November 30, 1984; revised manuscript received April 8, 1985; accepted October 30, 1985.

From the Medical and Research Service, VA Wadsworth Medical Center, University of Michigan School of Medicine, UCLA, and Center for Ulcer Research and Education, Los Angeles, California.

This work was supported in part by NIAMDD grant AM 25891, and Veterans Administration Research Funds.

Address for reprint requests: Dr. Felix W. Leung, Wadsworth VAMC, 691/111C, Wilshire and Sawtelle, Los Angeles, California 90073 . other hand, Konturek et al (3) found that nicotine infusion in the dog produced no change in pentagastrin- and histamine-stimulated gastric mucosal blood flow as measured by the aminopyrine clearance technique. Using the reflectance spectrophotometry technique in man, Kawano et al (8) reported an early reduction in gastric mucosal hemoglobin concentration with cigarette smoke. In contrast, Sonnenberg and Husmert (5) found in man that nicotine inhibited gastric acid secretion more than gastric mucosal blood flow as measured by neutral red clearance during pentagastrin infusion. The discrepancy among the existing data may be due to differences in experimental design and in the methods used to measure blood flow.

Significant reductions in mucosal blood flow have been shown to increase susceptibility of the gastric mucosa to injury $(9,10)$. Nicotine (6) and cigarette smoke (7) potentiated the formation of secretagogue-induced gastric as well as duodenal ulcerations. Hence we tested the hypothesis that nicotine and cigarette smoke may significantly reduce gastric mucosal blood flow. 
We examined the effect of both nicotine and cigarette smoke on gastric mucosal blood flow (GMBF) in this study using the recently validated hydrogen gas clearance technique (11-13). Despite an isolated report (14) that hydrogen gas clearance is unable to detect increases in gastric mucosal blood flow, the ability of this technique to detect decreases in gastric mucosal blood flow in the presence of vasopressin (12-14), prostacyclin (14), and hypotension (10) has been well demonstrated.

\section{MATERIALS AND METHODS}

Male Sprague-Dawley rats, 240-320 g, fasted overnight in metal tubes without water, were anesthetized with 1.5 $\mathrm{g} / \mathrm{kg}$ urethane subcutaneously. A tracheostomy was performed and a PE 250 tube was inserted into the trachea to facilitate the breathing of air, hydrogen gas, and/or cigarette smoke. The right carotid artery was cannulated for blood pressure monitoring using PE 90 tubing in the hemorrhagic hypotension study and PE 50 tubing for all other animals. The animal was then prepared for measurement of GMBF by the hydrogen gas clearance technique as previously described (12).

Briefly, a midline incision was made and the stomach exteriorized. Care was taken to minimize trauma to the stomach during surgery. The forestomach was incised and the stomach interior gently washed with saline at room temperature. A tygon tubing with an attached soft rubber balloon was inserted into the forestomach and secured by a suture. Two contact platinum electrodes were passed through the rubber tubing and placed gently against the gastric mucosa, one in the corpus, the other in the antrum. Two $\mathrm{Ag}-\mathrm{AgCl}$ reference electrodes were placed inside the peritoneal cavity. The stomach was then replaced in the abdominal cavity and the incision closed with a metal clip. The electrodes were connected to a polarographic unit (Val Tech Electronics, Sherman Oaks, California) and the electrode current was monitored on a chart recorder (Gilson Medical Electronics, Inc., Middleton, Wisconsin). A 23-gauge needle attached to a PE 50 tube was placed in the femoral vein for infusion of Ringer's lactate or nicotine. A rectal thermometer was inserted and body temperature maintained at $35-37^{\circ} \mathrm{C}$ by an external heat lamp.

Antral and corpus mucosal blood flow were measured using the hydrogen gas clearance technique with contact platinum electrode and $3 \%$ hydrogen in air $(10,12)$. Hydrogen gas at this concentration is nonflammable and does not produce hypoxia. The hydrogen clearance technique makes use of the dissociation of molecular hydrogen into hydrogen ions and electrons which occurs on the surface of the platinum electrode: $\mathrm{H}_{2} \rightarrow \mathrm{PS}_{\rightarrow} 2 \mathrm{H}^{+}+2 e^{-}$. With a completed circuit, the current is recorded on the chart recorder. The reported (15) linearity of the electrode current in the presence of hydrogen concentration in the range of $0-6 \%$ in an in vitro system at $\mathrm{pH} 7.4$ was similarly confirmed in our preliminary experiments for hydrogen concentrations in the range of $0.75-3 \%$ at $\mathrm{pH} 2$ and 7.2. The magnitude of the current is proportional to the concentration of molecular hydrogen in the tissue surrounding the electrode, in this case the gastric mucosa.

Three percent hydrogen gas in air is breathed by the animal until the current tracing rises to a plateau. The plateau indicates that the tissue is saturated with hydrogen gas. When the external hydrogen gas is turned off, the current gradually returns to its baseline value. For baseline gastric mucosal blood flow measurements, the saturation curves take about $15 \mathrm{~min}$ to reach plateau, and the desaturation curves take $15 \mathrm{~min}$ to return to baseline. For blood flows that are reduced, eg, under conditions of hypotension, the rise and fall of the tracing may each take up to $30 \mathrm{~min}$. In the studies reported in the present paper, the saturation and desaturation curves were each monitored throughout their entire time course. Since blood flow is the only route for removal of the hydrogen gas from the tissue, the rate of fall off of the current indicates the rate of blood flow through the mucosa.

Fourteen points (at 50 second intervals apart) along the desaturation curve, starting at time zero, ie, time when the desaturation curve begins to fall, were plotted on semi-logarithmic paper. The semi-logarithmic plot was monoexponential. The best monoexponential fit was carried out by visual inspection. The half-time in minutes, $T 1 / 2$, was determined. Mucosal blood flow in milliliters per minute per 100 grams gastric mucosal tissue is related to the half-time, $T 1 / 2$ in minutes, by the equation $(0.693 / T 1 / 2)$ $\times 100$. A more detailed discussion of this technique may be found in references 11,12 , and 15 .

Cigarette smoke was administered through a glass cylinder $20 \mathrm{~cm}$ long and $2.5 \mathrm{~cm}$ in cross-sectional diameter. The open end of the cylinder was placed over the rat's snout and tracheostomy tubing. A $Y$ tube was connected to the cylinder at a side hole near the tracheostomy. One limb of the $Y$ tube was connected to a 6-ml syringe and the other to a lighted cigarette. Cigarette smoke was aspirated into the syringe and then delivered into the glass cylinder near the nose and tracheostomy opening. Three percent hydrogen in air was administered at a second side hole during the saturation phase of the hydrogen clearance curve. During the desaturation phase, hydrogen gas was discontinued and air was passed through the smoke filled cylinder at a similar rate.

In all blood flow studies, corpus and antral mucosal blood flows were measured before, during, and after either hypotension, intravenous nicotine, or inhaled smoke administration. In addition, carotid artery blood pressure and rectal temperature were monitored throughout the experiment.

Study I: Positive Control. Effect of Treatment Known to Decrease Gastric Mucosal Blood Flow. Hypotension, produced by hemorrhage, was carried out in order to show that a decrease in gastric mucosal blood flow from baseline values could be demonstrated with the preparation and technique used in this study. Approximately 2-3 ml of blood were removed from six animals by bleeding into a heparinized syringe from the carotid cannula so as to reduce blood pressure $40-50 \%$, and this level of hypotension was maintained for $30 \mathrm{~min}$. The blood was reinfused for the posttreatment measurement.

Study II (a and b): Intravenous Nicotine Study. Nicotine 
was infused at two doses. Group IIa $(N=6)$ received 4 $\mu \mathrm{g} / \mathrm{kg} / \mathrm{min}$ of nicotine, and group $\mathrm{IIb}(N=7)$ received 40 $\mu \mathrm{g} / \mathrm{kg} / \mathrm{min}$. These doses were chosen because they significantly potentiated the formation of duodenal and gastric ulcerations induced by secretagogues infused subcutaneously for $24 \mathrm{hr}$ in the conscious rat (6). Nicotine was infused for $1 \mathrm{hr}$ in all animals, hydrogen gas was administered during the first $30 \mathrm{~min}$, and mucosal blood flow was measured during the last $30 \mathrm{~min}$. Lactated Ringer solution was infused at a rate of $1.5 \mathrm{ml} / \mathrm{hr}$ in control animals and during the baseline periods in the experimental animals.

Study III: Smoke Inhalation. Mucosal blood flow was determined before, during, and after each of two smoke inhalation periods. Each type of smoke was administered evenly (60 six-ml puffs per $15 \mathrm{~min}$ ) over a half-hour period. Six animals received the smoke from two tobacco cigarettes first (1.1 mg nicotine/cigarette) followed by the smoke from two nontobacco (nicotine free) cigarettes (Free, G.T.G., Inc., Los Gatos, California). The other six animals received the smoke treatment in the reverse order. The smoke was delivered through the glass cylinder covering the snout and tracheostomy tubing.

Statistical Analysis. A paired $t$ test was used to compare blood flow during the experimental period with that of the baseline period.

\section{RESULTS}

Antral mucosal blood flow was greater than corpus mucosal blood flow (Tables 1 and 2), a finding that is consistent with those of previous studies using hydrogen gas clearance for mucosal blood flow measurement in anesthetized animals (10-12). Baseline flow rates in all experimental groups were similar to those of control animals (Table 2). In the hemorrhagic hypotension group, significant $(P<$ 0.05 ) reductions in mucosal blood flow in the antrum $(24 \pm 7 \%)$ and in the corpus $(33 \pm 8 \%)$, and in mean arterial blood pressure $(42 \pm 5 \%)$ were demonstrated (Table 1). Such a correlation has been reported previously (10). This result thus indicates that the technique used is able to detect decreases in mucosal blood flow.

Study II (a and b): Intravenous Nicotine. Nicotine had no significant effect on either corpus or antral mucosal blood flow at the doses given (Table 2). Although blood flow tended to decrease at the higher dose of nicotine $(40 \mu \mathrm{g} / \mathrm{kg} / \mathrm{min})$, none of the differences between treatment and pre- or posttreatment periods were statistically significant.

Mean blood pressure was constant throughout the measurement periods. Animals receiving 40 $\mu \mathrm{g} / \mathrm{kg} / \mathrm{min}$ of nicotine exhibited a transient increase in blood pressure within 1 min followed by a gradual return to baseline 5-10 min after onset of the
TABle 1. EfFect of HemorRhagic Hypotension and Retransfusion of Shed Blood on Gastric Mucosal BLOOD FLow

\begin{tabular}{cclccc}
\hline Study & $N$ & & Baseline & $\begin{array}{c}\text { Hypo- } \\
\text { tension }\end{array}$ & $\begin{array}{c}\text { Retrans- } \\
\text { fusion }\end{array}$ \\
\hline I & 6 & $\begin{array}{l}\text { Antral MBF } \dagger \\
\text { \% change }\end{array}$ & $31 \pm 3$ & $23 \pm 2$ & $27 \pm 1$ \\
& & & $(24 \pm 7)$ & \\
& $\begin{array}{l}\text { Corpus MBF } \\
\text { \% change }\end{array}$ & $23 \pm 1$ & $16 \pm 2$ & $18 \pm 3$ \\
& & & $(33 \pm 8)$ & \\
& MBP & $107 \pm 2$ & $63 \pm 6$ & $99 \pm 11$ \\
& $\%$ change & & $(42 \pm 5)$ & \\
\end{tabular}

*Values during hypotension were significantly different from baseline value, $P<0.05$, paired $t$ test.

$\dagger \mathrm{MBF}$; mucosal blood flow in $\mathrm{ml} / \mathrm{min} / 100 \mathrm{~g}$ (mean $\pm \mathrm{SEM}$ ); MBP; mean carotid arterial blood pressure in $\mathrm{mm} \mathrm{Hg}$ (mean \pm SEM).

nicotine infusion. Blood pressure during the actual flow measurement, however, was not different from baseline in these animals.

Study III: Smoke Inhalation. Although half the animals received both types of cigarette smoke in a different order than the other half, no order effect was observed in the measurements of gastric mucosal blood flow. Therefore, for each type of cigarette smoke, data from all 12 animals were combined for analysis. Cigarette smoke, either containing nicotine, or nicotine-free, had no significant effect on either corpus or antral mucosal blood flow (Table 2).

\section{DISCUSSION}

Smokers have a higher incidence of ulcers (16), a slower healing rate of ulcers (17), and an increased mortality rate due to ulcers (18) than nonsmokers. While nicotine by itself does not cause experimental ulcers, it potentiates the formation of secretagogueinduced duodenal as well as gastric ulcers in the rat (6). Pathophysiologic studies have indicated that nicotine increases duodenogastric reflux $(1,2)$. Gastric acid secretion was reported to either increase (4), decrease (5), or remain unchanged (3) upon nicotine infusion.

Reduced gastric blood flow brought about by hemorrhage renders the mucosa more susceptible to injury $(9,10)$. Conversely, increasing mucosal blood flow by isoproterenol infusion protects against gastric mucosal injury (19). Based on anatomical studies, Piasecki (20) postulated an ischemic basis for the pathogenesis of peptic ulcer disease.

The hydrogen gas clearance technique, as used in this study, yielded data consistent with previous 
Table 2. Effect of Nicotine and Cigarette Smoke on Gastric Mucosal BLOOD FLOW

\begin{tabular}{|c|c|c|c|c|c|c|}
\hline \multirow[b]{2}{*}{ Study } & \multirow[b]{2}{*}{$N$} & \multirow[b]{2}{*}{ Drug } & & \multicolumn{3}{|c|}{ Mucosal blood flow* } \\
\hline & & & & Baseline & Treatment $\hat{T}^{\prime}$ & Baseline \\
\hline \multirow[t]{4}{*}{$\mathrm{IIa}$} & 6 & Ringers & Antrum & $28 \pm 3$ & $26 \pm 2$ & $26 \pm 3$ \\
\hline & & $(1.5 \mathrm{ml} / \mathrm{hr})$ & Corpus & $20 \pm 1$ & $19 \pm 2$ & $18 \pm 1$ \\
\hline & 6 & Nicotine & Antrum & $27 \pm 1$ & $25 \pm 3$ & $25 \pm 2$ \\
\hline & & $(4 \mu \mathrm{g} / \mathrm{kg} / \mathrm{min})$ & Corpus & $18 \pm 1$ & $18 \pm 1$ & $19 \pm 1$ \\
\hline \multirow[t]{4}{*}{ IIb } & 7 & Ringers & Antrum & $25 \pm 1$ & $25 \pm 1$ & $26 \pm 1$ \\
\hline & & $(1.5 \mathrm{ml} / \mathrm{hr})$ & Corpus & $20 \pm 1$ & $20 \pm 1$ & $19 \pm 1$ \\
\hline & 7 & Nicotine & Antrum & $29 \pm 1$ & $25 \pm 1$ & $27 \pm 2$ \\
\hline & & $(40 \mu \mathrm{g} / \mathrm{kg} / \mathrm{min})$ & Corpus & $23 \pm 1$ & $20 \pm 1$ & $20 \pm 1$ \\
\hline \multirow[t]{4}{*}{ III } & 12 & Nicotine-free & Antrum & $31 \pm 2$ & $27 \pm 1$ & $28 \pm 1$ \\
\hline & & smoke & Corpus & $24 \pm 1$ & $23 \pm 1$ & $20 \pm 1$ \\
\hline & 12 & Nicotine & Antrum & $29 \pm 1$ & $29 \pm 1$ & $29 \pm 1$ \\
\hline & & smoke & Corpus & $22 \pm 1$ & $22 \pm 1$ & $22 \pm 1$ \\
\hline
\end{tabular}

*Mucosal blood flow in $\mathrm{ml} / \mathrm{min} / 100 \mathrm{~g}$ (mean $\pm \mathrm{SEM}$ ).

$\uparrow$ Values during treatment were not significantly different from baseline values.

baseline blood flow measurements by hydrogen gas clearance in the anesthetized rats (10-12). Blood flow to the antral mucosa was consistently higher than that to the corpus mucosa, and both remained stable in control animals (Tables 1 and 2). The ability of the hydrogen gas clearance technique to detect decreases in gastric mucosal blood flow in the presence of vasopressin (12-14), prostacyclin (14), and hemorrhagic hypotension (10) has been reported. In the present study a significant $(P<$ 0.05 ) decrease in mucosal blood flow following hemorrhagic hypotension was also adequately demonstrated (Table 1). In contrast, nicotine, at doses known to potentiate the formation of secretagogueinduced gastric and duodenal lesions, and cigarette smoke had no significant effect on basal antral or corpus mucosal blood flow.

As mentioned previously, the relationship between smoking and nicotine, and gastric blood flow has been studied with mixed results. Using the neutral red clearance technique in man, nicotine (2-10 $\mu \mathrm{g} / \mathrm{kg} / \mathrm{min}$ ) decreased pentagastrin-stimulated neutral red clearance in a dose-dependent manner (5). However, since gastric acid secretion decreased more than neutral red clearance, the conclusion was that gastric mucosal blood flow measured by neutral red clearance increased relative to the reduced gastric acid secretion. A study in dogs reported that nicotine $(25$ and $50 \mu \mathrm{g} / \mathrm{kg} / \mathrm{min}$ for 10 min) increased total gastric blood flow as measured by an electromagnetic flow probe (4). Kawano et al (8), using the reflectance spectrophotometry technique, found that in man the inhalation of three puffs of cigarette smoke resulted in an immediate decrease in gastric mucosal hemoglobin concentration with rapid recovery upon cessation of smoking. Using the aminopyrine clearance technique in dogs, Konturek et al (3) found that nicotine infusion had no effect on gastric mucosal blood flow during pentagastrin or histamine stimulation.

In comparing findings from previous studies to those of the present one, there are several differences in experimental design that may account for some of the discrepancies. First, the time course of drug administration and subsequent blood flow measurement was variable. Jacobson and Pawlik (4), infused nicotine ( 25 and $50 \mu \mathrm{g} / \mathrm{kg} / \mathrm{min}$ ) for only $10 \mathrm{~min}$, during which time blood flow was continuously measured. This was done in dogs, not in rats. Kawano et al (8) measured mucosal hemoglobin concentration in man following inhalation of three puffs of cigarette smoke. In the present study, flow was measured during the last $30 \mathrm{~min}$ of a 1-hr nicotine infusion period. The difference in the amount or timing of nicotine administration prior to flow measurement may account for the difference in response.

The techniques used to measure gastric blood flow also varied. The techniques include neutral red clearance, aminopyrine clearance, electromagnetic flow probe, reflectance spectrophotometry, and hy. drogen gas clearance. Each of these techniques are based on different assumptions and measure different circulatory phenomena-the clearance technique measures mucosal blood flow, the electromagnetic flow probe measures total flow, and reflectance spectrophotometry measures mucosal hemoglobin concentration. Additionally, species dif- 
ferences may be responsible for some of the variability between results.

As mentioned previously, although blood flow exhibited a tendency to decrease in animals infused with nicotine at $40 \mu \mathrm{g} / \mathrm{kg} / \mathrm{min}$ (15\% drop from baseline), the decrease was not statistically significant. It is possible that a real type II error might be made because the number of animals examined was small $(N=7)$. To show that a $15 \%$ drop from baseline is truly present, at least 40 animals would have to be examined. Furthermore, using the hemorrhagic hypotension model, a $60 \%$ drop in gastric mucosal blood flow from baseline was required before a significant increase in susceptibility to acid induced mucosal injury was observed (10). Thus a 15\% decrease in gastric blood flow alone may be of only minimal importance in disrupting the integrity of the gastric mucosa.

In summary, a possible reduction in gastric mucosal blood flow by nicotine and cigarette smoke was examined in rats as a mechanism by which smoking might render the gastric mucosa more susceptible to injury. The results show that in the anesthetized rats hypotension but not intravenous nicotine or cigarette smoke, in the doses given, reduce gastric mucosal blood flow measured by hydrogen gas clearance. It is conceivable that an effect of nicotine and smoking at different doses and for different time intervals for the application of these substances may be present in either anesthetized or conscious animals. Further studies in man are needed to directly test the hypothesis that the injurious effect of smoking on the gastric mucosa is mediated by a reduction in basal gastric mucosal blood flow.

\section{ACKNOWLEDGMENTS}

The authors are indebted to Dr. Janet Elashoff for statistical assistance, Anita Starlight and Marilyn Tandy for secretarial assistance.

\section{REFERENCES}

1. Read NW, Grech P: Effect of cigarette smoking on competence of the pylorus: Preliminary study. Br Med J 3:313-316, 1973

2. Dippy JE, Rhodes J, Cross S: Bile reflux in gastric ulcer: The effect of smoking, metoclopramide and carbenoxolone sodium. Curr Med Res Opin 1:569-575, 1973
3. Konturek SJ, Solomon TE, McCreight WG, Johnson LR, Jacobson ED: Effect of nicotine on gastrointestinal secretions. Gastroenterology 60:1098-1105, 1971

4. Jacobson EO, Pawlik WW: Effect of nicotine on gastric hemodynamics and secretion in the dog. Gastroenterology 86:1123, 1984 (abstract)

5. Sonnenberg A, Husmert $\mathrm{N}$ : Effect of nicotine on gastric mucosal blood flow and acid secretion. Gut 23:532-535, 1982

6. Robert A: Potentiation, by nicotine, of duodenal ulcers in the rat. Proc Soc Exp Biol Med 139:319-322, 1972

7. Toon RW, Cross FS, Wangensten OH: Effect of inhaled cigarette smoke on production of peptic ulcer in the dog. Proc Soc Exp Biol Med 77:866-869, 1951

8. Kawano S, Sato N, Fukuda M, Shichiri M, Kamada T, Abe $\mathrm{H}$ : Effect of cigarette smoking on the gastric hemodynamics. Jpn J Gastroenterol 79:192, 1982

9. Ritchie WP Jr: Acute gastric mucosal damage induced by bile salts, acid, and ischemia. Gastroenterology 68:699-707, 1975

10. Leung FW, Itoh M, Hirabayashi K, Guth PH: Role of blood flow in gastric and duodenal mucosal injury in the rat. Gastroenterology 88:281-289, 1985

11. Murakami M, Moriga M, Miyake $T$, Uchino H: Contact electrode method in hydrogen gas clearance technique: A new method for determination of regional gastric mucosal blood flow in animals and humans. Gastroenterology $82: 457-467,1982$

12. Leung FW, Guth PH, Scremin OU, Golanska EM, Kauffman GL Jr: Regional gastric mucosal blood flow measurements by hydrogen gas clearance in the anesthetized rat and rabbit. Gastroenterology 87:28-36, 1984

13. Ashley SW, Cheung LY: Measurement of gastric mucosal blood flow by hydrogen gas clearance. Am J Physiol 247:G339-G345, 1984

14. Takeshita H, Kotani Y, Okabe S: Comparative study of hydrogen and aminopyrine clearance methods for determination of gastric mucosal blood flow in dogs. Dig Dis Sci 29:841-847, 1984

15. Aukland K, Bower BF, Berliner RW: Measurement of local blood flow with hydrogen gas. Circ Res 14:164-187, 1964

16. Friedman GD, Siegelaub AB, Seltzer CC: Cigarettes, alcohol, coffee and peptic ulcer. N Engl J Med 290:469-473, 1974

17. Korman MG, Shaw RG, Hansky J, Schmidt GT, Stern AI: Influence of smoking on healing rate of duodenal ulcer in response to cimetidine or high-dose antacid. Gastroenterology 80:1451-1453, 1981

18. Harrison AR, Elashoff JD, Grossman MI: Peptic ulcer disease. In Smoking and Health, Report of the Surgeon General. Washington, D.C., U.S. Public Health Service, Office of Smoking and Health. DHEW Publication No. 79-50066: pp 9-3-9-21, 1979

19. Ritchie WP Jr, Shearborn EW III: Influence of isoproterenol and cholestyramine on acute gastric mucosal ulcerogenesis. Gastroenterology 73:62-65, 1977

20. Piasecki C: Role of ischemia in the initiation of peptic ulcer. Ann R Coll Surg Engl 59:476-478, 1977 